Original article

https://www.journal-imab-bg.org

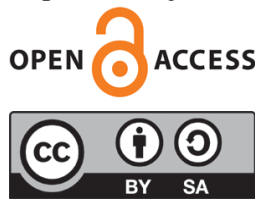

\title{
THE IMPACT OF THE EUROPEAN DIRECTIVE AGAINST FALSIFIED MEDICINES ON THE PHARMACEUTICAL WHOLESALERS IN BULGARIA
}

\author{
Krasimira Valcheva \\ Department of Public Administration, Faculty of Management and \\ Administration, University of National and World Economy, Sofia, Bulgaria.
}

\begin{abstract}
:
In the last few decades, the problem with falsified medicine became a global threat that accounts for millions of human lives and billions of financial loses for the national health authorities and pharmaceutical industry. Different measures were developed to fight their uncontrolled spread but had only limited success. The resolution that united the pharmaceutical supply chain actors worldwide is the introduction of track-and-trace systems, based on product serialization and verification. The European Union also adopted this solution, and its official operation began in 2019. Each Member State has specifics that have to be accounted for in the national transposition process and should influence the system design and functionalities. In Bulgaria, the responsible authorities seriously delayed to adopt an adequate legal and regulatory framework to support its smooth operation. This created many problems for some of the key supply chain participants - the wholesalers. Since the European system is not a full track-and-trace solution, their role in the verification process is limited and left to the national authorities to decide how to regulate it. At present, more than one year after the launch of the system, the national bylaws that should regulate their activities with reference to the European policy are still not enforced. The wholesalers are left to align their operations in a regulatory vacuum that may compromise the effectiveness of the policy and lead to sanctions for noncompliance.
\end{abstract}

Keywords: falsified medicines, pharmaceutical regulation, verification system, pharmaceutical wholesaler,

\section{INTRODUCTION}

In the 1980s, the World Health Organization focused its attention on falsified medicines and initiated a worldwide fight against their uncontrolled spread. The lack of internationally accepted definition created many difficulties, but recently a common understanding was reached - they represent medicinal products with a false representation of their identity, source, composition and history. During the last few decades, international organizations, national authorities and industry engaged in dif- ferent incentives to restrict their pandemic distribution [1]. The results were far from satisfactory - the falsified medicines industry became the most lucrative one with annual revenues from 150 to 200 billion Euro [2]. Millions of people lose their lives because of falsified medicines, and the national health sectors suffer significant loses trying to cope with their adverse effects.

In 2011 the European Parliament and the Council introduced Directive 2011/62/EU and initiated a coherent multilevel fight against their penetration in the legal supply chains of the European Union (EU) Member States. It amended the fundamental pharmaceutical Directive 2001/83/EC and became known as the Falsified Medicine Directive (FMD). The main goal was a comprehensive legal and regulatory framework to be established that engages all stakeholders in the pharmaceutical sector. In the following years, the European authorities adopted supplementary legal acts and guidelines to further clarify and regulate the proper and timely implementation of the new measures.

Delegated Regulation (EU) 2016/161 is the key act that imposed the creation of a centralized European trackand-trace system based on serialization and verification of prescription medicines. Unlike other countries, the EU chose the so-called book-end approach, a variation that excludes the wholesalers from obligatory verification except in special cases with increased risk of falsification. This influenced the smooth implementation of the regulations and created serious confusion in the supply chain that led to the adoption of a six-month transitional period after the official launch of the system in Bulgaria.

\section{MATERIALS AND METHODS}

The research has two interconnected goals - to reveal the impact of the new measures on the pharmaceutical wholesalers in Bulgaria and to identify the major difficulties they encountered in the preliminary and initial phases of their implementation. The dividing line between the two periods is the official start of the verification system in EU Member states on 9th of February 2019.

The selected method is a focus group that consisted of seven participants with in-depth expertise in the field 
- the author, four representatives of wholesale companies and since the sector actively participates with the rest of the supply chain actors, a representative from a big national pharmaceutical manufacturer and one pharmacist were also invited. The group of the wholesalers included members of the Bulgarian Association of Pharmaceutical Wholesalers (BAPW) and one from the Bulgarian Association for Medicines Parallel Trade Development (BAMPTD).

The focus group meeting was held in March 2019, a month after the new European verification system was officially launched. The discussion was organized as per preliminary composed questionnaire on the basis of a literature review on the subject and personal expertise of the author. The results are analysed and supported with additional materials from previous research on the transposition process of Directive 2011/62/EU and its accompanying regulations in Bulgaria as well as with official and media publications. The executive director of the Bulgarian Association of Pharmaceutical Wholesalers (BAPW) also took part in the research by kindly providing answers to the questionnaire via e-mail. Unless otherwise indicated, all citations in the main text represent direct statements of the participants in the focus group.

\section{RESULTS FROM THE STUDY \\ Preparatory phase analysis}

Bulgaria, along with Denmark, France, Slovakia and Romania, is among the early adopters of Directive 2011/62/EU [3]. The corresponding changes in the national Law on Medicinal Products in Human Medicine (LMPHM) were enacted on $21^{\text {st }}$ of December 2012, a few days before the set deadline for its national enforcement by the Member States. The prompt adoption should have provided the national authorities with sufficient time to inform all stakeholders for the upcoming changes and take the necessary steps to secure a smooth transition. The proactive institutional reaction is also a condition for a new interaction model between the stakeholders (mutual creation of value) based on dialogue, access, risk assessment and transparency [4]. The focus group discussion, however, revealed a different situation. When the participants were asked when they have received initial information on the subject and from what source a significant information gap was identified. The wholesalers, members of BAPW stated that they were informed for the upcoming regulations at the very stage of their formulation. The organization, as part of the European Healthcare Distribution Association, actively participated in the policymaking process and strived to "prevent many administrative burdens and excessive financial investments". The representatives of the manufacturers reported that they received information later mainly from private organizations interested in the process - companies for serialization equipment, market data and software solutions. A strong impression made the fact that the two national responsible authorities - Ministry of Health $(\mathrm{MOH})$ and Bulgarian Drug Agency (BDA), were not mentioned as sources of any relative information. The participants dis- cussed that only after the establishment of the Bulgarian Medicine Verification Organization (BgMVO) in 2016 the information flow became increased, more targeted and coordinated. This initiated the process of consistent preparatory activities among the pharmaceutical supply chain actors. The wholesalers' representative said that they launched internal procedures to comply with the new requirements in 2017. A team was formed with employees from different departments of the company - IT, corporate activities, warehousing, etc.

Legal and regulatory changes of such magnitude usually provoke diverse reactions, and the following discussion focused on identifying their scope. The participants stated that their expectations included a "saturated palette of reactions, from positive to extremely negative." The first were connected with the anticipation for increased efficiency and transparency of the pharmaceutical supply chain. The representative of the parallel traders pointed out that the new regulations would help the sector to eliminate the companies that operate on "the edge of the law". This is extremely important for them since due to unscrupulous operators, they are often associated with the distribution of falsified and substandard medicines. At a press conference held on $6^{\text {th }}$ of February prof. Ilko Getov, chairman of the Bulgarian Pharmaceutical Union and a member of BgMVO board, supported such expectation: "This is a kind of stress test for the pharmaceutical supply chain because all types of incorrect practices will be eliminated in 99\% when the verification system is fully operational"[5]. The negative expectations that the experts shared were connected mainly with the major financial and human resource investments that they have to undertake to align their operations with the new requirements. Although they are most significant for the manufactures - the equipment of just one packaging line costs approximately 500000 Euros [6], the other actors in the supply chain would also have to adjust their budgets. If the production sector lobbied for the new regulations and therefore was willing and ready to make the necessary expenses, the other stakeholders expressed some disagreements. The pharmacists' representative stated that they became only recently aware of their new responsibilities and were unpleasantly surprised by the costs they have to bear. Their discontent became public two weeks after the verification system was launched on $9^{\text {th }}$ of February 2019. Pharmacists across the country openly protested by closing their venues for a day and created difficulties with access to medicines for the patients.

The pharmaceutical sector is regarded as one of the most highly regulated worldwide, and the question if such additional, stricter measures are needed was addressed. Moreover, in Bulgaria, there were only two confirmed cases of falsified medicines [7]. The reason why such information is missing was explained by the director of the Association of Research-based Pharmaceutical Manufacturers in Bulgaria: "The only way to find out if there are such...is to buy representative packages from most pharmacies in Bulgaria and analyze them. Such large-scale 
checks are not done because they are very expensive" [8]. This could also explain why Bulgaria adopted in time and in full FMD. It represents a comprehensive supranational instrument specially designed to fight the falsified medicines, and each Member state would save significant costs for drug screening. Since the implementation costs would be borne by the business, the states will fulfill their obligation to grant the consumers access to quality, safe and effective medicines without any major financial investments. Despite the lack of data to support the need for specific regulations against falsified medicines in Bulgaria, all experts agreed that they are necessary and the sector "even needs to be more regulated". They were well aware that the lack of statistics does not mean that the problem does not exist. Two of the participants discussed that they had encountered falsified medicines in their practice. As per data provided by the World Health Organization, approximately $1 \%$ of the falsified medicines penetrated in the pharmaceutical supply chains in the developed countries and $10 \%$ of all medications sold worldwide are fake [9]. There is no reason to assume that Bulgaria is an exception. If we assume that they represent only $1 \%$, this would mean that at least two million packs distributed annually in our country might be with compromised quality. To support the necessity of the new regulations, the experts also pointed out the expected benefits from their implementation. The most significant discussed were the possibilities for increased brand protection, optimization of recalls and returns, demand forecasts and sales marketing effectiveness.

When asked to assess their company's readiness before the start of the verification system on $9^{\text {th }}$ of February 2019 , the representatives of the wholesalers and manufactures stated that its $100 \%$. The members of BAPW "are actively fulfilling their obligations and the recommendation to verify at least one pack from a received product to ensure that it is authentic". Bulgaria was among the first five countries who successfully connected its national verification system to the EU Hub on $18^{\text {th }}$ of April 2018. The executive director of BgMVO stated that" starting the pilot on schedule provides enough time to all participants in the pharmaceutical logistics chain to onboard, test, train and prepare themselves on time. This will allow the pressure-free deployment of the system, avoiding otherwise inevitable extra costs associated with short deadlines" [10]. Despite the active and timely actions of BgMVO, one of the experts shared a problem that they came across only two months before the official launch of the system. It was connected with the interpretation of the term "designated wholesaler" mentioned in art. 20 of Delegated Regulation (EU) 2016/161. The question was whether their company could be deemed as one. This is important since the EU traceability system is not a complete version of track-and-trace and wholesalers should only carry out verification and deactivation of codes in certain cases. If the wholesaler is recognized by a manufacturer as a designated partner, the obligations to verify the products they receive from them will be waived. This will result in saving significant time and costs and will facilitate warehouse operations. The company tried to acquire more information from the responsible authorities but without success. They resolved the issue independently by sending official letters to their partners requesting clarification of their status and inclusion in the respective lists and information that they submit to the centralized European verification system.

The final discussion concerning the preparatory phase focused on identifying the most significant difficulties that the experts encountered while aligning their activities with the new regulations. Some were concerned with a large number of participants in the process and the needed "technical time for employee training and system testing". Others were troubled by the lack of information on some aspects of the verification process. However, all of them stated that the most significant problems originated mainly from the lack of regulatory support by the $\mathrm{MOH}$ and the BDA since these institutions were "not sufficiently active in enforcing the law and rules". Despite the time they had to take the necessary steps to facilitate the implementation process, serious omissions were identified. Although the initial amendments in LMPHM were adopted on time, BgMVO started its operation without the proper legal grounds. It is important since the Organization is a non-profit entity and therefore has no legal rights, unless granted by the state, to regulate the activities required as per Delegated Regulation (EU) 2016/161. These EU legal acts are with a general application - they should be directly adopted by all Member States, but this does not exclude the need for the introduction of a national legal framework for their implementation that is adapted to the specificities of the local pharmaceutical supply chains. Key national regulations were not updated on time which left to the goodwill of the stakeholders to align their operations with the new requirements that created many organizational problems after the start of the verification system in Bulgaria.

\section{Initial phase analysis}

The focus group results regarding the preparatory phase revealed active commitment of the wholesalers in the implementation of the new regulations against falsified medicines. Despite the legal and regulatory vacuum, the verification system was officially launched on $9^{\text {th }}$ of February 2019 in Bulgaria as well as in the other Member States. Unfortunately, the start was far from successful. The wholesalers faced many problems - what were they and how the most urgent could be resolved was the focus of the second part of the discussion. This group operates as intermediaries in the supply chain between the manufactures and the end dispensers - the pharmacists, and the participation in the discussion from their representatives is important since some of the problems directly influence the dynamic of their cooperation.

With reference to the results from the preparatory phase, the main problems after the official start of the verification system that the wholesalers discussed were still caused by the authorities' delay to regulate key issues of the process. Under art. 23 of Delegated Regulation (EU) 
2016/161 Member States may require, where necessary to accommodate the particular characteristics of the supply chain on their territory, that a wholesaler verifies the safety features and decommissions the unique identifier of a medicinal product before he supplies it to the beneficiaries. All respondents from the wholesalers stated that the lack of national legislation and specific regulation caused "unclarity and uncertainty" in their operations. Along with the LMPHM, a key bylaw act that regulates the wholesale pharmaceutical activities in Bulgaria is Regulation No. 39 from 2007 that sets the principles and requirements of Good Distribution Practices (GDP). According to Art. 198 of the national pharmaceutical law, the principles and requirements for GDP of medicinal products must be adopted in the form of regulation by the Minister of Health and in accordance with European Commission (EC) guidelines. They were published in 2013 and included a new chapter (Chapter 6) that stipulates how wholesalers should proceed with complaints, returns, suspected falsified medicinal products and their withdrawal from the supply chain [11]. Seven years later, Regulation No. 39 is not yet updated. This leaves to the national wholesalers to decide whether and how to comply with the European recommendation since the guidelines are not yet legally binding.

The participants were especially concerned how to proceed with the deactivation of the unique identification coded under art. 23 of the Delegated Regulation before they supply prescription medicines to any of the listed in the article persons or institutions- veterinaries, dentists, paramedics, governmental institutions maintaining stocks of medicinal products like armed forces, prisons, schools and etc.[12].One of the experts raised shared a problem that would concern, for example, the national medicine reserve maintained by the State Agency "State Reserve and War-time Stocks". When wholesalers win a tender to deliver medicines for the Agency, they are required to store and provide certain qualities for the needs of the respective national authorities. According to Delegated Regulation, they may be requested to deactivate their unique identification codes in the verification system at the time of the supply. Pursuant to the Regulation on the Terms and Conditions for Organization of the Activities of State Reserves and War-time Stocks, the delivered medicinal products should have at least $70 \%$ shelf life. This means that the wholesalers may receive back medications whose codes have been deactivated but are suitable to be distributed in the pharmacy network. Without an active identifier, this would be no longer possible, and they should be discarded at the expense of the wholesaler. The only possible solution that united the experts was to the authorities to develop a national "special regulation to govern verification and to impose sanctions".

The adoption of sanctions could also help in the resolution of another problem discussed by the wholesale experts - the "reluctance of pharmacies to modernize, use pharmacy software and verify". This is a major problem since they are the end-point of verification and if they do not comply, this might threaten the whole implemen- tation process of FMD in Bulgaria. They were so discontent that on $20^{\text {th }}$ of February 2019, two weeks after the start of the system, the pharmacist across the country organized public protests. This was expected since they stated their resistance prior to the start of the system, and no specific measures were taken by the authorities. The pharmacists had enough time to align their operations with the new requirements, and what is odd is that they implemented earlier another measure of Directive 2011/ $62 /$ EU without objections. All online pharmacies should have posted till $1^{\text {st }}$ of July 2015 a common European logo on their official websites. It should guarantee that they are authorised by the competent national institution to sell medicines online. Although there was a delay, research in February 2019 showed that the logo is present on the websites of more than $90 \%$ of the operational retailers. This measure did not impose additional costs, but we could conclude that the pharmacy sector should have been aware of the new regulation earlier than they stated. As a result of their resistance and because of the next discussed problem, the authorities adopted a six-month transitional period to resolve the emerged issues.

The other major problem in the initial phase was the generated alerts by the verification system. The resolution of how to react in such cases was defined as priority by the experts since it results in a delay of the delivery of medicines to patients. These alerts appear when a wholesaler or a pharmacist tries to authenticate a prescription drug prior to its sell. An illustrative example was provided by one of the participants: "We recently had one case where the system generates an alert for a life-saving medication in a large hospital, which is urgently needed for medical treatment. We were contacted by the hospital pharmacy to check the problem and to resolve it as soon as possible. We responded quickly, but overall, the lack of clear communication rules in such situations is a serious obstacle for all actors in the chain." According to Art. 18, 24 and 30 of the Delegated Regulation the manufacturers, wholesalers and pharmacists should contact the relevant competent authorities, which in Bulgaria is BDA. However, the organization responsible for the establishment, management, operation and maintenance of the national verification register is BgMVO despite the fact that it is not legally authorized. Two days before the official launch of the system it published "Instructions for the management of signals for verification and withdrawal of medicines after 09 February 2019" but the experts in discussed that they do not find them sufficient enough. The resolution of the problem could be the establishment of a communication platform that connects in real-time all the participants in the supply chain in case of an alert. On $12^{\text {th }}$ of March BgMVO announced that a call centre started to operate so as to facilitate the process. A Bulgarian software company came up with another option an especially designed software. It is a much cheaper and efficient solution as it does not implicate additional investments by the stakeholders and saves significant time to react in case of suspected medicines by including all relevant actors from the supply chain (fig. 1) in a real- 
time environment. It is user friendly and could identify right away if the alert is caused by a problem with the unique identifier of the product - the most common reason before and after the start of the system.

Fig.1. A communication protocol in case of generated alerts.



The transitional period ended on the 9th of August 2019. The national authorities should have adapted the respective legal and regulatory measure to facilitate the implementation of the verification system, but unfortunately, more than a year later, they are still not ready. The amendments of the LMPHM were drafted and published for public discussion but are not yet enforced. One-third of the pharmacies are not yet connected to the system and only half of the those who perform scans of the prescription medicines they sell [13]. The lack of sanctions and technical problems delayed the proper functioning of the system. At the same time, the first falsified medicines detected in the EU came from Bulgaria. Although our country gained a significant advantage in the preparatory phase, the authorities' legal and regulatory delay resulted in Bulgaria, along with Romania to be regarded as lagged in the implementation of FMD and the national pharmaceutical verification system.

\section{CONCLUSION}

Timely and adequate actions by the national regulatory authorities to support the transfer of the European policy against falsified medicines are a key factor that contributes to its coherent and synchronized implementation. Supranational initiatives of such magnitude are often with general content and require additional national regulations to support their national transposition process. If the authorized institutions do not take the necessary steps to adapt them to the local specifics, there is an increased risk of difficulties and conflicts between the participants in the process. In Bulgaria, such confusion and confrontation have not been avoided, and the national transfer of Directive 2011/62 / EU and its accompanying regulations has not yet been fully accomplished.Some of the problems remain unsolved, and the stakeholders in the pharmaceutical supply chain still operate in a regulatory vacuum without being properly engaged in the execution of the new measures. 


\section{REFERENCES:}

1. Nayyar GML, Breman JG, Herrington JE. The global pandemic of falsified medicines: laboratory and field innovations and policy perspectives. Am J Trop Med Hyg. 2015 Jun; 92(6 Suppl):2-7. [PubMed] [Crossref]

2. Behner P, Hecht ML, Wahl F. Fighting counterfeit pharmaceuticals: New defenses for an underestimated and growing menace. Strategy\& $P w C$. June 29 2017. [Internet]

3. Directive 2011/62/EU of the European Parliament and of the Council of 8 June 2011 amending Directive 2001/83/EC on the Community code relating to medicinal products for human use, as regards the prevention of the entry into the legal supply chain of falsified medicinal products. [Internet]

4. Valkov A. [Strategic Management of Healthcare Organizations. The Customer-driven Healthcare Management]. Avangard Prima. 2010. pp.28-32. [in Bulgarian]

5. Bulgarian Medicines Verification Organization. Press conference "Official start of the medicine verification system in Bulgaria". February 6, 2019. [Internet]

6. Van Baelen M, Dylst P, Lopes Pereira C, Verhaeghe J, Nauwelaerts K, Lyddon S. Fighting Counterfeit Medicines in Europe: The Effect on Access to Medicines. Medicine Access@ Point of Care. June 28, 2017. [Crossref]

7. Bozukova M. [The authorities are aware of two cases of falsified medicines in the pharmacies.] [in Bulgarian] Mediapool.bg. January 16, 2019. [Internet]

8. Nikolova D. [Bulgaria does not monitor falsified medicines because it is expensive.] [in Bulgarian] Capital. January 18, 2019. [Internet]

9. Lavelle K. Europe Fights Back against Counterfeit Medication with the European Falsified Medicines Di- rective. Peak-Ryzex Direct. April 22, 2016. [Internet]

10. Paunova I. The Bulgarian Medicines Verification System Goes Live. Bulgarian Medicines Verification Organization. April 18, 2018. [Internet]

11. Guidelines of 5 November 2013 on Good Distribution Practice of medicinal products for human use (Text with EEA relevance). [Internet]

12. Commission Delegated Regulation (EU) $2016 / 161$ of 2 October 2015 supplementing Directive 2001/ 83/EC of the European Parliament and of the Council by laying down detailed rules for the safety features appearing on the packaging of medicinal products for human use (Text with EEA relevance). [Internet]

13. Bozukova M. [One-third of the drugs are scanned for falsification when dispensed.] [in Bulgarian] Mediapool.bg. February 14, 2020. [Internet]

Please cite this article as: Valcheva K. The Impact of the European Directive Against Falsified Medicines on the Pharmaceutical Wholesalers in Bulgaria. J of IMAB. 2021 Jan-Mar;27(1):3598-3603.

DOI: https://doi.org/10.5272/jimab.2021271.3598

Received: 01/04/2020; Published online: 04/03/2021

Address for correspondence:

KrasimiraValcheva,

Department of Public Administration, Faculty of Management and Administration, University of National and World Economy, Sofia, Student Town, 1700 Sofia, Bulgaria

E-mail:kvalcheva@unwe.bg 